\title{
Agroecologia e tecnologia social como caminhos para o desenvolvimento rural integral:Uma aproximação
}

\author{
Agroecology and social technology as paths to the integral rural development: an approach
}

\author{
Ednalva Felix das Neves ${ }^{\mathrm{I}}$, Márcia Maria Tait Lima ${ }^{\mathrm{II}}$, Gabriel Eduardo Gonçalves ${ }^{\mathrm{II}}$
}

\begin{abstract}
Resumo:
Tanto sob a perspectiva empírica, como teórico-conceitual, a Tecnologia Social (TS) pode ser entendida como aquela tecnologia que melhor se alinha à proposta de resolver os problemas sociais: primeiro, a TS possibilita o processo de construção social da tecnologia, isto é, os atores sociais que utilizarão a tecnologia participam da construção da mesma. Além disso, ao invés de garantir os objetivos de geração de lucro, ela é voltada para resolver problemas sociais e, dentre estes, a exclusão social. A TS se alinha à temática do desenvolvimento rural, tanto pela crítica aos problemas sociais gerados pelo capitalismo, como, pela crítica a sua insustentabilidade ambiental. Além disso, as discussões sobre o desenvolvimento rural, durante a década de 1990 marcaram a diferenciação entre a agricultura familiar (geralmente, pequena) e a grande agricultura - elemento essencial para mostrar a importância de se desenvolver políticas públicas para a agricultura familiar. A Agroecologia também se posiciona criticamente contra os problemas gerados pelo capitalismo, destacado que o modelo da grande agricultura, com seus objetivos de lucro, não se alinha à proposta de sustentabilidade. Em contraposição, é são os pequenos agricultores familiares que vêm se dedicando a desenvolver práticas agrícolas alternativas, que se alinham à proposta de uma sociedade sustentável (sob a perspectiva econômica, ambiental, social, etc.).
\end{abstract}

Palavras-chave: Tecnologia social; Desenvolvimento rural; Agroecologia

\begin{abstract}
:
From both an empirical and theoretical-conceptual perspective, Social Technology (TS) can be understood as the technology that best aligns with the proposal to solve social problems: first, TS enables the process of social construction of technology, that is, the social actors who will use the technology participate in its construction. Moreover, rather than guaranteeing profit-making goals, it is aimed at solving social problems and, among them, social exclusion. The TS is aligned with the theme of rural development, for the criticizing the social problems generated by capitalism, and by criticizing its environmental unsustainability. In addition, discussions about rural development during the 1990s marked the differentiation between family farming (often small) and large farming - an essential element to show the importance of developing public policies for family farming. Agroecology also takes a critical stand against the problems generated by capitalism, emphasizing that the model of large agriculture, with its profit objectives, is not in line with the sustainability proposal. In contrast, it is the small family farmers who have been devoting themselves to developing alternative farming practices that align with the proposal of a sustainable society (from the economic, environmental, social, etc.) perspective.
\end{abstract}

Keywords: Social technology; Rural development; Agroecology

\footnotetext{
IDoutora em Desenvolvimento Econômico pela Universidade Estadual de Campinas (UNICAMP). Pesquisadora de (PNPD/Capes) e professora colaboradora no PPGE\&D da Universidade Federal de Santa Maria (UFSM) - ednalvafelix@gmail.com. IIDoutora em Política Científica e Tecnológica pela Universidade Estadual de Campinas (DPCT/UNICAMP). Pesquisadora (PNPD/Capes) e professora colaboradora no Mestrado em Divulgação Científica e Cultural - marcia.tait@gmail.com.

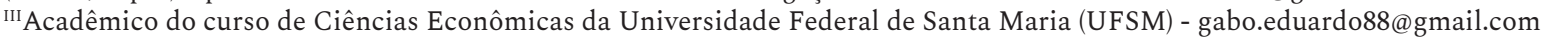




\section{Introdução}

A abordagem do texto inicia-se a partir de um questionamento bastante importante sobre a vinculação da temática do desenvolvimento rural e da agroecologia com a Tecnologia Social. Basicamente, a discussão parte de uma pergunta central: qual a relação existente entre o desenvolvimento rural e a agroecologia com as tecnologias sociais? A partir disso, vale adiantar que o trabalho parte do pressuposto de que a Tecnologia Social (TS) se alinha às propostas do desenvolvimento rural e da Agroecologia.

Para fins de análise neste texto, entende-se a TS como um conjunto de técnicas e metodologias que podem ser aplicadas (e/ou reaplicadas) para a solução de problemas sociais, a partir da interação com os atores que a utilizarão. $\mathrm{O}$ desenvolvimento rural pode ser sintetizado aqui como um conjunto de ações propositalmente voltados para promover o desenvolvimento do ambiente rural. Contudo, embora não tenha um viés excludente, tem um caráter voltado para a pequena agricultura, por entender sua diferenciação com relação à grande agricultura, especialmente, no que diz respeito a suas fragilidades e dificuldades (ITS, 2004). Por sua vez, de forma resumida, pode-se definir a Agroecologia, tanto como uma agricultura de base ecológica ou sustentável, como um processo sistêmico, social, que gera resultados para o bem comum (e não apenas para um pequeno grupo) (SCHNEIDER, 2010; CAPORAL e COSTABEBER, 2000).

Assim, o objetivo deste trabalho é relacionar as discussões sobre a temática da Tecnologia Social com o mundo rural, mais especificamente, com a temática do Desenvolvimento Rural e da Agroecologia.

O texto não pretende, contudo, trazer uma resposta a esta pergunta, mas suscitar elementos para promover o debate e a reflexão sobre esta possível vinculação dos temas. Para tal, primeiro, o texto traz a contribuição das reflexões sobre Tecnologia Social. Em seguida, são apresentadas as contribuições sobre Desenvolvimento Rural e, então, sobre Agroecologia. Ao final, discute-se a relação entre as três temáticas.

\section{Desenvolvimento}

\section{Tecnologia Social}

A tecnologia, definida por Sandroni como a "ciência ou teoria da técnica", diz respeito à capacidade que os seres humanos têm para inventar, criar e aperfeiçoar instrumentos para explorar a natureza e produzir bens - ou o "conjunto de processos mecânicos e intelectuais". Logo, implica em objetos utilizados pelos seres humanos para atuar na transformação da natureza (trabalhar): "ferramentas, máquinas, matérias-primas, métodos de observação, controle e processos de interação entre o homem e o objeto de seu trabalho, manual ou intelectual" (SANDRONI, 1999, p. 593).

A dinâmica de geração de conhecimento e criação de tecnologias, no modelo de desenvolvimento capitalista tem gerado riquezas e melhorias para uma parcela pequena da população, enquanto exclui uma parcela maior de pessoas. Nesse sentido, a tecnologia possui uma forma balizadora, dentro do modelo de desenvolvimento capitalista, para contribuir aos processos de concentração de renda e riqueza. Ou seja, neste modelo, enquanto se gera riquezas, também se gera exclusões (econômicas e sociais) (RUTKOWSKI, 2005; DAGNINO, 2010).

Ao analisar o contexto histórico de surgimento da sociedade capitalista, nota-se que seu desenvolvimento e consolidação ocorreu em paralelo ao desenvolvimento e aperfeiçoamento da tecnologia. Assim, é possível afirmar que a tecnologia tem sido uma importante aliada do sistema capitalista de produção. Tendo em vista isso, no texto "A Tecnologia Social e seus desafios", Dagnino (2010) parte da crítica a este modelo para criar o conceito de Tecnologia Social.

Ou seja, o autor critica a tecnologia desenvolvida e utilizada pelo sistema capitalista de produção - que ele denominou Tecnologia Convencional (TC) - para construir, em oposição a ele, o conceito de Tecnologia Social. Como TC o autor entende aquela tecnologia que é desenvolvida e utilizada pelas empresas privadas (capitalistas). De acordo com Dagnino, esta tecnologia não serve para promover a inclusão social. É fácil entender isso - uma vez que o sistema capitalista é, por si mesmo, excludente, a tecnologia desenvolvida para servi-lo não pode promover um processo inverso, de inclusão social (isso feriria sua própria maneira de ser). "Ou seja, existem aspectos na TC, crescentemente eficiente para os propósitos de maximização do lucro privado para os quais é desenvolvida nas empresas, que limitam sua eficácia para a [inclusão social]” (DAGNINO, 2010, p. 53; grifos nossos). De acordo com Rutkowski (2005):

Essa dinâmica econômica baseia-se em intenso processo de inovação tecnológica, o qual reduz cada vez mais os ciclos de vida e aumenta a diversidade dos produtos, e, ao mesmo tempo, reduz as oportunidades de inserção grupos sociais, cujas características socioeconômicas e culturais não correspondam às condições exigidas por esses novos padrões de produção e de consumo. Tal complexidade tecnológica transforma, assim, a tecnologia em vetor de exclusão social (RUTKOWSKI, 2005, p. 181).

Como exclusão social entende-se aqui o resultado dos processos econômicos que excluem uma parcela da sociedade dos seus resultados. Por sua vez, esta exclusão ocasiona exclusão da possibilidade de consumo dos bens essenciais à 
vida, o que, por sua vez, gera exclusão social. Assim, parte-se da identificação de que o desenvolvimento econômico no sistema capitalista tem gerado estas mazelas e que é preciso construir alternativas para garantir a inclusão social.

Dagnino, apresenta, então, características da TC que fazem com que ela seja inadequada para promover a inclusão social. Primeiramente, a TC é mais poupadora de mão-de-obra, isso porque sua projeção foi feita de uma maneira tal que ela deve promover a constante substituição da mão-de-obra por máquinas, numa busca por redução dos custos de produção, para garantia da maximização dos lucros. E isso ocorre porque "o lucro das empresas depende de uma constante redução da mão-de-obra incorporada ao produto, ou do tempo de trabalho socialmente necessário para produzir mercadorias". Ademais, a TC maximiza a produtividade em relação à mão-de-obra ocupada, isto é, para a empresa capitalista, uma maior produtividade significa ocupação de menos mão-de-obra e sua substituição por máquinas, o que resulta em desemprego (DAGNINO, 2010, p. 55). Sendo assim, existe um conflito entre geração de emprego (ocupação da mão-de-obra), que garantiria a inclusão social dos trabalhadores - e o lucro das empresas.

A TC é intensiva em insumos sintéticos que, geralmente, são produzidos pelas grandes empresas, o que acarreta duplo problema: ela é ambientalmente insustentável e condiciona à dependência dos pequenos produtores em relação às empresas produtoras. No que refere à questão da sua (in)sustentabilidade, isso ocorre porque o próprio modelo do sistema capitalista, pautado na competição desenfreada, corrobora para que haja uma constante e crescente degradação ambiental e geração de resíduos - a questão ambiental é vista como externalidade para o sistema capitalista, que não computa a deterioração ambiental em seus custos de produção.

Outra característica da TC é que ela possui escalas ótimas de produção sempre crescentes: isso implica dizer que a tecnologia necessária para uma determinada planta produtiva é cada vez maior, de maneira que a instalação de uma planta produtiva se torna inviável para os pequenos produtores. Assim, sua utilização resulta em constantes situações de desvantagens para os pequenos produtores, de modo a ser "quase um impedimento para a [sua] sustentabilidade" (DAGNINO, 2010, p. 56; grifos nossos).

Além disso, ela é "monopolizada pelas grandes empresas dos países ricos", já que "possui padrões orientados pelo mercado externo de alta renda". Ou seja, são os países ricos quem determinam as tecnologias que serão adotadas (tecnologias da vez), e que se espalharão pelo mundo. Tendo como objetivo a maximização dos lucros e manutenção do poder de mercado, as grandes empresas destes países orientam suas P\&D para a produção de bens de consumo para as classes de altas rendas (baseadas em tecnologias HiTec). Isso conduz a outra questão: algumas empresas são mais ricas e, portanto, podem gastar mais em P\&D que alguns países: "As 20 empresas que mais gastam em pesquisa no mundo gastam mais do que 2 países", o que demonstra a monopolização da C\&T (DAGNINO, 2010, p. 57).

Por outro lado, as tecnologias voltadas para satisfazer o consumo popular, as necessidades básicas (especialmente dos menos favorecidos) "estão paradas no tempo". Estas tecnologias poderiam garantir a produção de infraestrutura, agregar valor às matérias-primas dos países de Terceiro Mundo e, inclusive, viabilizar a produção dos empreendimentos produtivos menores, capazes de absorver mais a mão-de-obra, garantindo trabalho e renda, e assim, a inclusão social. Contudo, não há interesse dos países produtores de tecnologia em viabilizar estas tecnologias, uma vez que elas não garantem retornos financeiros capazes de maximizar os lucros das grandes empresas.

Logo, se a TC é excludente e apresenta uma série de limitações para se promover a inclusão social ou mesmo a construção de uma sociedade menos desigual e sustentável, torna-se evidente a necessidade de se desenvolver outra tecnologia capaz de atender às necessidades básicas da população, especialmente, dos mais pobres. Isto é, tecnologias que possam "atender à dimensão humana do desenvolvimento e aos interesses coletivos de garantir, de maneira sustentável, melhor qualidade de vida, tanto presente quanto futura” (RUTKOWSKI, 2005, p. 181).

Diante destas considerações, seria possível questionar, como faz Rutkowski (2005), se a tecnologia seria uma "maldição fatal". Avançando nas reflexões sobre o papel da tecnologia, a própria autora conclui que é possível desenvolver outra abordagem sobre o conhecimento científico e o desenvolvimento tecnológico, que possa alavancar outro tipo de desenvolvimento, capaz de promover o desenvolvimento local e propiciar a inclusão social e sustentabilidade.

Logo, é possível desenvolver tecnologias que tenham como principal função "suprir necessidades básicas da população", que tenham como principal objetivo "atender à dimensão humana do desenvolvimento e aos interesses coletivos de garantir, de maneira sustentável, uma melhor qualidade de vida, tanto presente quanto futura", ao invés de atender aos objetivos do capital. A TS tem grande potencial de resolver problemas sociais, especialmente, de promover a inclusão social (RUTKOWSKI, 2005, p. 190-191). E é neste contexto que surge a proposta de se desenvolver Tecnologia Social (TS).

Na sequência, a pergunta que carece de resposta é, se a TC não serve para a inclusão social, que aspectos possuem a TS que fazem com que ela se alinhe a uma proposta neste sentido? Compreender o papel da TS é inferir que seu termo indica, implicitamente, algumas concepções acerca de sua dinâmica.

Em primeiro lugar, o termo Tecnologia Social traz o tema da inclusão social e melhoria da qualidade de vida das pessoas. Ele parte do reconhecimento de que existem problemas sociais carentes de soluções, sendo a exclusão social o mais importante deles. Em segundo lugar, por adicionar o termo "Social" à Tecnologia, o conceito carrega, inevitavelmente, a ideia de construção social - ou seja, trata-se de uma tecnologia que deve ser construída pelo con- 
junto daqueles que irão utilizá-la, de maneira que possa refletir seus princípios e aspectos culturais. Isto é, a TS deve ser desenvolvida a partir da interação com os usuários (ou seja, “com”, e não apenas "para”, aqueles que a utilizarão). Para tal, é importante que haja uma fusão dos diferentes saberes - sejam eles saberes científicos ou acadêmicos (de pesquisadores sensibilizados e engajados na tarefa de desenvolver tecnologias para solucionar problemas sociais), ou populares (daqueles que necessitam da tecnologia em questão). A fusão entre os saberes populares e especializados pode se transformar numa importante ferramenta para a inclusão social (RUTKWOSKI, 2005).

(...) as TS’s são essencialmente participativas e priorizam a colaboração e a cooperação, como forma de construção e validação de escolhas coletivas do conhecimento, sejam estes saberes científicos, tecnológicos ou populares, de forma a transferir à população, principalmente àquela excluída do processo econômico e social, os benefícios gerados pela C\&T, de maneira a contribuir para redução das desigualdades econômicas, sociais, inter-regionais e interpessoais (RUTKWOSKI, 2005, p. 183).

A interação é um aspecto importante para garantir que as tecnologias a serem desenvolvidas respeitam as características e particularidades dos diferentes contextos, bem como suas dimensões econômicas, sociais, culturais, políticas, etc. Além desse espectro, as TS garantem o desenvolvimento das habilidades daqueles que as utilizarão, ao passo que participarem da sua construção.

Assim, no que se refere ao aspecto de construção social da tecnologia, é possível perceber seu importante papel de aliar "saber popular, organização social e conhecimento técnico-científico" para a solução de problemas sociais, apresentando-se como alternativas efetivas para os problemas sociais, conforme aponta a Fundação Banco do Brasil (FBB, 2019, online). Por outro lado, por possuir condições de reaplicação, a TS gera condições para se promover o "desenvolvimento social em escala".

Rutkowski também menciona o fato de que as TS “são essencialmente participativas”, e são validadas a partir de processos coletivos, priorizando a colaboração e cooperação dos diferentes saberes (científicos, tecnológicos, populares):

Outra característica sempre associada ao termo é a necessidade de seu desenvolvimento se dar a partir da interação com a população, a partir do reconhecimento de que a fusão do saber popular com o conhecimento especializado proporciona ferramentas poderosas para a inclusão social e o progresso humano (RUTKOWSKI, 2005, p. 183).

A fundação define TS como sendo "produtos, técnicas ou metodologias reaplicáveis, desenvolvidas na interação com a comunidade e que representem efetivas soluções de transformação social”. Elas podem incluir “soluções para problemas voltados a demandas de alimentação, educação, energia, habitação, renda, recursos hídricos, saúde, meio ambiente, dentre outras". Para a FBB (2019, online), o conceito de TS "remete para uma proposta inovadora de desenvolvimento, considerando uma abordagem construtivista na participação coletiva do processo de organização, desenvolvimento e implementação" de tecnologias, o que garante o aspecto “social” do termo. Desta forma, o conceito de TS pode ser resumido da seguinte maneira:

Um conjunto de técnicas e procedimentos, associados às formas de organização coletiva, que representa soluções para inclusão social e melhoria da qualidade de vida. Uma tecnologia de produto ou processo que de maneira simples e de fácil aplicação e reaplicação, com baixo custo e uso intensivo de mão-de-obra, tem impacto positivo na capacidade de resolução de problemas sociais. Uma tecnologia que depende tanto de conhecimentos gerados e difundidos na comunidade, os chamados conhecimentos populares, como daqueles técnico-científicos, desenvolvidos no ambiente acadêmico. Em suma, tecnologias sociais dizem respeito aos processos que visem não apenas à busca por modernos conhecimentos, como também à superação das desigualdades na distribuição da riqueza e da pobreza (RUTKOWSKI, 2005, p. 182).

Dagnino ainda elabora uma matriz com dimensões de análise da tecnologia social e seus respectivos "conjuntos”, caracterizados por grupos de elementos que devem ser considerados no desenvolvimento e análise de uma tecnologia social, sendo esses conjuntos: geração de conhecimentos, dinâmica sócio técnica e alternativas tecnológicas, que dizem respeitos às possibilidades de desenvolvimento de alternativas e adequações sócio técnicas, aos grupos sociais relevantes, as características do entorno, e as demandas possíveis soluções; e as sustentabilidades econômica, ambiental, cultural e política, que dizem respeito a interações entre determinantes sociais mais amplas como: geração de renda, cadeias produtivas, a capacidade de organização, aspectos legais, políticos e interações com esferas governamentais e estatais, questões de raça e gênero e as interações com o meio ambiente, que podem ser positivas ou predatórias e promotoras de degradação (DAGNINO, 2014, p. 193-194).

Esses conjuntos mostram a indissociável relação entre tecnologias, sujeitos e contextos de produção e são bastante próximos das “dimensões da agroecologia”, bem como do desenvolvimento rural, por ressaltar a necessidade de considerar a complexidade da natureza e da agricultura e a interação entre suas várias dimensões - social, cultural, ambiental e política - nas práxis da realidade rural e, especialmente, nas práticas agroecológicas. Essas dimensões 
são descritas pelos principais autores do campo de estudos da Agroecologia como Gliessman, Guzmán, Altieri, Caporal e Costabeber. Essa proximidade nos permite estabelecer pontos de reflexão e análise comuns entre os dois temas - tecnologia social e agroecologia - que ficarão mais claras ao final desse artigo quando desenvolvimentos o tema da agroecologia, seguramente essa relação também aparecerá nos casos concretos analisados no âmbito do projeto de pesquisa em desenvolvimento.

As dimensões da Agroecologia, assim como da tecnologia social, também partem de alguns princípios metodológicos, ou que dizem respeito ao modo de geração de conhecimento, sendo de forma sintética: o enfoque endógeno, valorização do conhecimento local e gerado "a partir de dentro"; a diversidade, que deve permear como princípio todos os âmbitos (ecológicos, agronômicos, econômicos e socioculturais) e o diálogo de saberes, fundamentalmente entre os saberes tecnocientíficos, tradicionais, camponeses e indígenas (TAIT, BIASE e FAGUNDES, 2017, p. 36-37).

\section{Desenvolvimento Rural}

As discussões sobre o rural ganharam, partir da década de 1990, novo enfoque, diferente daquele adotado em décadas anteriores, influenciado pelas transformações que a década trouxe - no âmbito político, social e econômico - para a atuação do Estado e mesmo das reflexões e pesquisas da época. Este novo enfoque, somado à realidade empírica, contribuíram para a construção da concepção acerca do desenvolvimento rural (SCHNEIDER, 2010). No campo da realidade empírica, pode dizer que contribuíram para tal, as pressões dos movimentos sociais por políticas públicas que considerassem as questões referentes às desigualdades na posse da terra, a pobreza rural e o êxodo rural - que, por sua vez, inchava as cidades e causava(ria) a pobreza urbana. Já no campo das pesquisas, destaca-se tanto as discussões sobre estas temáticas, bem como sobre os novos atores e realidades do rural brasileiro.

Três importantes aspectos contribuíram para esta nova concepção sobre desenvolvimento rural: primeiro, as especificidades dos anos oitenta, uma vez que esta década foi considerado a década perdida, em virtude dos problemas econômicos que enfrentou - recessão, inflação e redução do emprego. O segundo aspecto diz respeito ao processo de redemocratização do país, que fez com que os movimentos sociais, na década de 1990, adotassem ações mais proativas e propositivas (antes suas ações tinham um tom mais reivindicatórias e contestatórias). Por fim, "a incorporação da noção de sustentabilidade e meio ambiente", marcado, especialmente, pela realização da Conferência da ONU no Rio de Janeiro em 1992, trazendo o debate ambiental para as discussões de intelectuais, apontando o papel das instituições (em especial, do Estado) e de demais atores da sociedade.

De acordo com Schneider o surgimento de uma nova visão sobre o que significava o desenvolvimento rural no Brasil ocorreu motivada por alguns fatores, tais como, a emergência das discussões sobre a "agricultura familiar e de seu potencial como modelo social, econômico e produtivo para a sociedade brasileira" que, apesar de já existir, ganhou importância, firmando-se enquanto categoria política na primeira metade da década de 1990, guiando pesquisas e ações das políticas públicas, e tornando-se referência na contraposição ao agronegócio (SCHNEIDER, 2010). É preciso ressaltar a importância da agricultura familiar no cenário rural brasileiro, responsável pela produção de cerca de $70 \%$ dos alimentos no país, o que corrobora para sua relevância no espaço rural, bem como, para "o seu alicerce na alimentação e na temática da segurança alimentar, tanto nos espaços rurais quanto nos urbanos” (PENA, 2009, p. 196).

Duas correntes de pensamento contemporâneo norteiam as discussões sobre desenvolvimento rural: uma que enfatiza a dimensão territorial do desenvolvimento - isto é, nas redes e instituições formadas, bem como o tecido social formado; outra que foca no capital social - isto é, nas características da organização social. Assim, o desenvolvimento rural é entendido a partir de uma perspectiva de que a dinâmica territorial é mais importante que a setorial (ABRAMOVAY, 1999). A nova dinâmica territorial é marcada pelo dinamismo e diversificação das cidades, com projetos formulados de maneira descentralizada e que valorize aspectos locais e regionais. Esta concepção entende que o desenvolvimento rural deve integrar "o desenvolvimento territorial integrado sustentável", tendo como "linha condutora os diagnósticos da realidade produtiva, social, política e organizativa" (PENA, 2009, p. 197).

Abramovay destaca, com base nos censos agropecuários realizados desde 1950, que quando se observa pelo tamanho da propriedade e pela renda geradas, há diferença crucial na setorização do rural brasileiro - é grande a participação das propriedades com menos de 100 hectares de terra, mas a renda gerada por eles é pequena. Ou seja, esta situação indica que, para além da diferença no tamanho das propriedades, há uma diferença gritante na renda gerada, de maneira que indica uma situação de pobreza no campo, também entre proprietários de terras. Em suma, a grande maioria das famílias rurais sobrevivem com baixas rendas, que estão reféns do mercado e, muitas vezes "são levados a liquidar os ativos para saldar parte de pesadas dívidas" (ABRAMOVAY, 2001, p. 27). Assim, fica evidenciada uma situação de pobreza rural, que vai além daqueles que não possuem terras. Este setor é aquele que, geralmente, não tem acesso às tecnologias necessárias para produzir (HERRERA, 2010).

No Brasil a agricultura familiar, ainda que "perdendo terreno" em termos de volume de terra ocupada, conseguiu manter-se num lugar de destaque na produção de alimentos para consumo interno e também em termos de número de estabelecimentos rurais e geração de postos de trabalho. Isso pode ser observado no levantamento chamado de 
“radiografia da agricultura familiar”, elaborado pelo Ministério do Desenvolvimento Agrário (MDA) em 2009, a partir do Censo Agropecuário de 2006 e de outros levantamentos do Instituto Brasileiro de Geografia e Estatística (IBGE). Esta radiografia apontou que, comparado ao chamado agronegócio, a agricultura familiar domina as estatísticas em número geração de empregos. Do total de cerca de 5 milhões de estabelecimentos existentes no país, 4,3 milhões são de agricultura familiar (84\%) e 807 mil (16\%) são de agricultura não familiar ou patronal. Os pequenos ocupam 74\% da mão-de-obra do setor (12,3 milhões de pessoas), enquanto os grandes ocupam apenas $26 \%$ da mão-de-obra (4,2 milhões). Segundo o Censo Agropecuário brasileiro de 2006, os pequenos estabelecimentos agropecuários (até 200 hectares) representam menos de $30 \%$ do total de terras, e contraditoriamente, é onde se encontram mais de $70 \%$ dos trabalhadores.

Em 2006 a agricultura familiar produziu 33\% do arroz em casca, 69,6\% do feijão (considerados todos os tipos), $83 \%$ da mandioca, $14 \%$ da soja, $21 \%$ do trigo e $38 \%$ do café em grão, $57,6 \%$ do leite de vaca, $67 \%$ do leite de cabra e $16,2 \%$ dos ovos de galinha e detinha $29,7 \%$ do rebanho bovino, $51 \%$ das aves e $59 \%$ dos suínos. Contudo, vale mencionar que, grande parte dos agricultores familiares vive em situação de pobreza e miserabilidade. A relação deste setor com a tecnologia contribui, em grande medida para esta situação, conforme destaca Herrera (2010).

No que se refere às pesquisas sobre o tema, Schneider (2010, p. 505) destaca a importância da criação de "uma nova tipologia" sobre os estabelecimentos rurais, realizada pela FAO/INCRA ${ }^{1}$, que resultou em uma nova classificação do setor:

Este estudo foi fundamental por ter classificado os estabelecimentos rurais brasileiros segundo a forma de uso do trabalho (familiar versus contratado ou assalariado), ter sugerindo uma tipologia que separava a agricultura familiar (consolidados, em transição e periféricos) da patronal e por ter apresentado um conjunto de sugestões de políticas agrícolas e fundiárias específicas destinadas a esta categoria social (SCHNEIDER, 2010, p. 516).

Outros estudos se somaram a este, no mesmo sentido, sendo importante sinalizadores para a formulação de políticas públicas próprias para esta categoria, baseado na justificativa de que ela tinha suas especificidades que a diferenciavam da grande agricultura e, especialmente, era mais frágil. Dentre as principais políticas desenvolvidas para este setor, destaca-se o nascimento do Programa de Fortalecimento da Agricultura Familiar (PRONAF).

Outro fator mencionado por Schneider (2010) é a importante e crescente atuação do Estado na formulação de políticas públicas para a agricultura familiar, conforme mencionado, mas também, nas ações referentes à reforma agrária, segurança alimentar, etc.

Sob o governo Itamar Franco e depois Fernando Henrique Cardoso, o Estado passa a legitimar as reivindicações dos movimentos sociais e a promover várias ações inéditas no espaço rural. Uma das principais ações foi a aceleração da reforma agrária, o que ocorreu pós sanção da Lei Agrária e do Rito Sumário, em 1993, sendo em seguida criada a Secretaria Especial Extraordinária de Assuntos Fundiários, que viria a ser transformada no Ministério do Desenvolvimento Agrário (MDA) em 1998. Depois, através da criação da secretaria de desenvolvimento rural (SDR-MAPA), também transferida para o MDA. Por último, deve-se registrar a criação do PRONAF (Programa Nacional de Fortalecimento da Agricultura Familiar), em 1996, que passou a ser a principal política pública destinada aos pequenos agricultores no Brasil (SCHNEIDER, 2010, p. 516).

O papel do Estado cresceu e se diversificou durante as duas décadas seguintes, sendo marcada, especialmente, pela atuação dos governos de esquerda do Partido dos Trabalhadores, tratando, também, incluindo outras temáticas ligadas à questão rural, tais como: "políticas de segurança alimentar, combate às formas precárias de trabalho, regularização fundiária, apoio às populações tradicionais (quilombolas, ribeirinhos) e ações de desenvolvimento territorial” (SCHNEIDER, 2010, p. 516).

As mudanças no âmbito político e ideológico também vêm contribuindo para a compreensão sobre o desenvolvimento rural, segundo o autor. Estas mudanças foram importantes em dois sentidos: a primeira foi o entendimento de que existe uma diferenciação entre os setores produtivos rurais brasileiros - a produção da agricultura familiar era destinada a abastecer o mercado interno, enquanto que a grande produção empresarial (agronegócio ou agricultura industrial) produzia commodities para exportação; em segundo lugar, elas afetaram, também, as elites agrárias que, até então, eram contrárias às mudanças, especialmente referente às políticas sociais compensatórias - ela mudou de posição.

Por último, as discussões sobre sustentabilidade ambiental, com a conotação que ganhou em 1992, na Conferência da ONU em 1992 contribuíram para a nova compreensão sobre o rural, por dois motivos: primeiro, por apresentar uma crítica a modelo da revolução verde, o que coincide com "uma tentativa de internalização da questão ambiental aos modelos técnico-produtivos denominados alternativos, ecológicos, orgânicos e outras nomenclaturas”. Além disso, os pesquisadores do tema buscavam "converter a noção de sustentabilidade em referencial teórico e modelo de desenvolvimento". A influência deste debate sobre o tema rural foi que teve início uma associação entre os temas, tanto que se passou a falar em desenvolvimento rural sustentável (SCHNEIDER, 2010, p. 517).

1 FAO: sigla do termo em inglês "Food and Agriculture Organization". INCRA: Instituto Nacional de Colonização e Reforma Agrária. 


\section{Agroecologia $^{2}$}

Nesta seção aprofundaremos a discussão trazida brevemente no início deste artigo caracterizando a Agroecologia que é, simultaneamente, "uma prática agrícola, um campo de conhecimento científico e um movimento social" (WEZEL, et al., 2009; GLIESSMAN, 2000; 2002; TOLEDO, 2016). No centro da sua proposta estão o desenvolvimento rural sustentável, com base na equidade social (e de gênero), diversidade sociocultural e promoção da autonomia e soberania alimentar dos povos e comunidades. Toledo (2016, p. 43) sintetiza os pilares do conceito de agroecologia pontuando que:

(...) representa um salto epistemológico e metodológico que propicia novas maneiras de fazer ciência; também é uma prática. Ou seja, ela envolve inovação tecnológica e prática. No entanto, não se trata de uma inovação tecnológica que surge em centros de pesquisa e depois é repassada para os agricultores. A inovação tecnológica na agroecologia resulta tanto do conhecimento tradicional camponês quanto do conhecimento acadêmico. Finalmente, a agroecologia também é um movimento social. Isso fica claro, por exemplo, nos congressos e encontros de agroecologia que, basicamente, consistem em oportunidades para a reunião de acadêmicos, gestores públicos e representantes de organizações de agricultores e movimentos sociais.

De fato, o uso do termo "agroecologia" - que existe desde os anos 30 e passou a ser mais amplamente utilizado a partir da década de 90, no âmbito científico e interface entre ecologia e agronomia - não estabelece o início de práticas ou concepções que poderiam ser caracterizadas como agroecológicas, pois já eram tradicionalmente realizadas por camponeses/as e/ou agricultores/as familiares. Estas práticas são bastante anteriores ao próprio conceito, como mostram as técnicas e modos de produção próprios e históricos desenvolvidos por comunidade e famílias camponesas e indígenas que, nas últimas décadas, foram resinificadas dentro de órgãos de assistência técnica e de segmentos da academia. Por exemplo, a produção, armazenamento e intercâmbio de sementes crioulas ou práticas agrícolas familiares e comunitárias baseadas em recursos locais e sem utilização de insumos químicos, que são formas de organização social, manejo do solo e agrícola e constituem um conjunto de conhecimentos e tecnologias que existem e são aprimoradas há muitas gerações.

Para Guzmán et al. (2000) a Agroecologia pode ser definida como o manejo ecológico dos recursos naturais através de formas de ação social coletiva que apresentam alternativas a atual crise civilizatória. O enfoque agroecológico representaria uma resposta à lógica neoliberal e aos processos de globalização econômica, que também enfatiza a função do conhecimento científico e questiona os cânones da ciência convencional.

Para Altieri (2002) e Altieri e Nicholls (2000) a Agroecologia é uma estrutura metodológica de trabalho para a compreensão mais profunda da natureza dos agroecossistemas e dos princípios segundo os quais eles funcionam; seria "uma nova abordagem" que integra os princípios agronômicos, ecológicos e socioeconômicos à compreensão e avaliação do efeito das tecnologias sobre os sistemas agrícolas e a sociedade como um todo. Para os autores, a diversidade cultural e grupos locais nutrem as agriculturas locais e são fundamentais para os processos agroecológicos.

A agroecologia, de acordo com Caporal e Costabeber (2004) pode ser compreendida como uma área do conhecimento transdisciplinar que busca apoiar a transição dos modelos de desenvolvimento rural e de agricultura convencionais para estilos de desenvolvimento e de agriculturas sustentáveis. Para os autores, é fundamental a noção de processo, de "vir a ser" que se estabelece na ideia de "transição agroecológica".

A transição enfatiza o processo e as etapas que buscam transformar culturas já baseadas no modelo agroquímico de produção em culturas de base ecológica (CAPORAL e COSTABEBER, 2000, p. 12). A dimensão e ecológica é chave e busca principalmente "maior eficiência do uso de insumos", reduzindo a necessidade de insumos químicos através do "manejo integrado de pragas" e "gestão da fertilidade do solo", desenho de sistemas com um conjunto ótimo de variedades biológicas, incluindo plantas e animais e incentivando sinergismos e auto regulação do próprio agroecossistema (ALTIERI, NICHOLLS, MONTALBA, 2017, p. 349).

Realizar todas essas transformações ecológicas, culturais e socioeconômicas, quando se pretende mudar uma forma de manejo da terra e suas práticas agrícolas não é um processo que acontece da noite para o dia. Por isso, dentro da Agroecologia se trabalha com a noção de "transição agroecológica", um processo contínuo e multidimensional de mudanças nas práticas de manejo de um agroecossistema que busca atingir seus vários níveis em termos de territórios (macro, meso e micro, envolvendo desde a unidade produtiva familiar até o entorno mais direto e região) e também todas as dimensões e processos envolvidos na Agroecologia (COSTABEBER, 2006).

A Agroecologia e suas dimensões - social, ambiental, econômica e política - foram associando-se a outros temas que mobilizam conhecimentos e práticas sociais coletivas. Em âmbito científico e também político, no Brasil, entidades como Articulação Nacional de Agroecologia, os Encontros Nacionais de Agroecologia e a Associação Nacional de Agroecologia (ABA) - que este ano realiza seu XI Congresso - vem articulando interessados no entendimento

2 Para essa parte do artigo utilizamos principalmente de revisões bibliográficas trabalhadas no livro Tait (2015) e no artigo de Tait e Jesus (2017). 
e difusão das práticas agroecológicas. Essas entidades têm ampliado a aliança da Agroecologia com outros temas e lutas como: soberania e segurança alimentar e nutricional, Economia Solidária, Feminismo, Justiça Ambiental, Comunicação e Cultura, Saúde Coletiva e Direito à Cidade, podemos ainda incluir o próprio tema da geração de conhecimentos de forma colaborativa e da tecnologia social (ver figura abaixo):

Figura 1 - Diálogos e convergências: dimensões que interagem com a Agroecologia

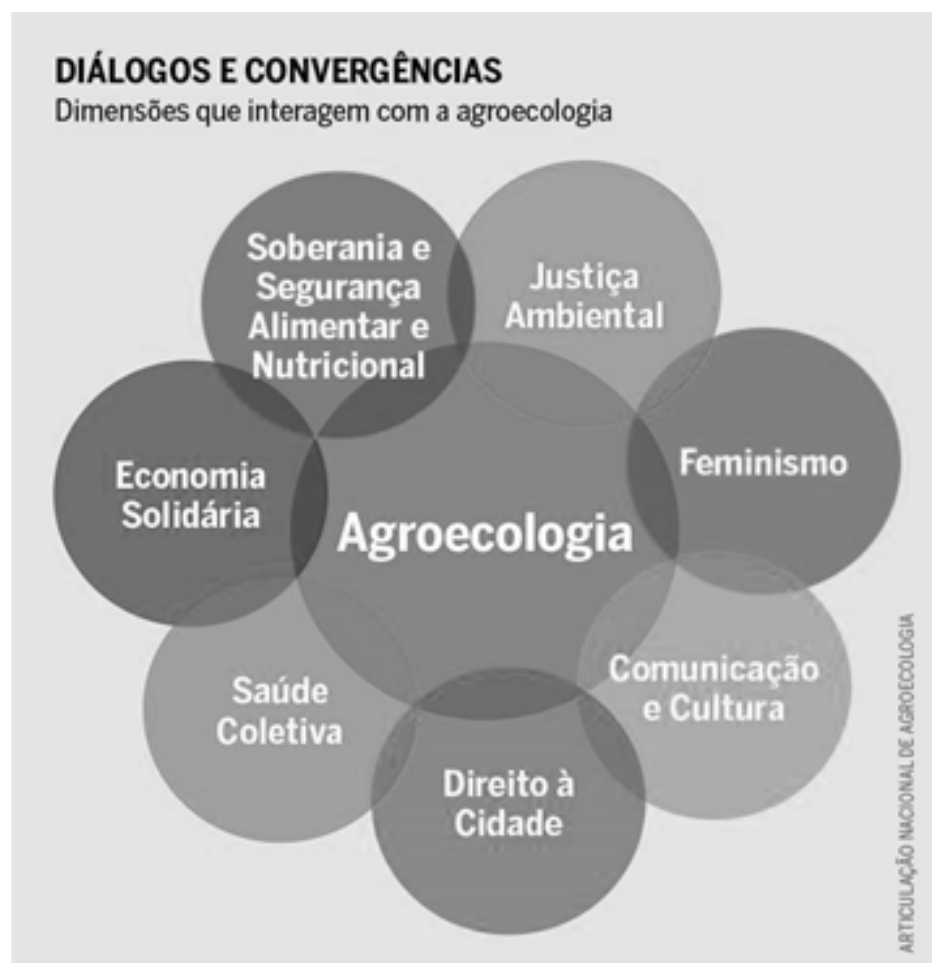

Fonte: Articulação Nacional de Agroecologia (2019, online).

Finalmente é importante ressaltar que as mobilizações em torno a Agroecologia conseguiram gerar uma massa crítica e pressão social que influenciou a definição de políticas, mais ou menos, alinhadas a demanda por apoio a produção familiar, orgânica e finalmente agroecológica que teve um momento emblemático com a instituição da Política Nacional de Agroecologia e Produção Orgânica (Pnapo) em 2012, por meio do Decreto no 7.794, com o objetivo de integrar e articular políticas indutoras da transição agroecológica e da produção orgânica e de base agroecológica no Brasil. A criação dessa política é fruto de processos anteriores, principalmente a partir de 2003 com primeira gestão do presidente Luiz Inácio Lula da Silva, e da atuação importante do Ministério do Desenvolvimento Agrário (extinto em 2016 e “redefinido" enquanto uma Secretaria Especial), da atuação dos órgãos de Assistência Técnica e Extensão Rural (ATER) e também da reestruturação do CONSEA (Conselho Nacional de Segurança Alimentar e criação da Câmara Interministerial de Segurança Alimentar e Nutricional). Nesse mesmo contexto foram criados dois programas fundamental para fomentar a produção e demandas contínuas do agricultura familiar e agroecológica - o Programa de Aquisição de Alimentos (PAA) e o Programa Nacional de Alimentação Escolar (PNAE) (BERGAMASCO, 2017; MOURA, 2016).

Como buscamos demonstrar com essa discussão, a agricultura em bases agroecológicas implica muitas vezes em transformações amplas e radicais, embora possam - e muitas vezes comecem - com algumas práticas e transformações locais e de forma gradual dentro de processos de "transição agroecológica". Outras vezes, exigem um alto grau de resistência para seguir em territórios e produzindo de forma familiar e tradicional, fora da agricultura industrial, recebendo suas pressões, com pouco e descontínuos apoios dos governos pelas políticas públicas.

Essa descrição, e breve trajetória aqui delineadas, também evidenciam que Agroecologia não é uma receita simplista e exige acima de tudo "um enfoque amplo e integral da agricultura e do desenvolvimento rural, onde a interação entre seres humanos e terra ou sociedade e natureza não seja tratada apenas como uma questão econômica cuja eficiência deriva da manipulação físico-química e do aporte de capital” (URCHEI, 2017, p. 25). 


\section{Agrotecnologia e tecnologia social para um desenvolvimento rural integral}

Nesta seção abordaremos os elementos que indicam uma aproximação das temáticas aqui tratadas. Em primeiro lugar, as discussões sobre a temática da TS se constroem a partir de uma crítica aos problemas sociais gerados pelo sistema capitalista de produção (especialmente, a exclusão social) e, por assim ser, se posiciona criticamente contra este sistema. Parte importante das discussões sobre o tema (especialmente, nas abordagens de Dagnino), atrela-se às discussões sobre TS à geração de trabalho e renda como forma de se promover a inclusão social, dando ênfase, especialmente, à importância dos pequenos empreendimentos produtivos - isso fica mais evidente nas bibliografias que relacionam TS à Economia Solidária e à autogestão, por exemplo. Mas também relaciona com questões do próprio mundo do trabalho, como a crítica à fragmentação do trabalho, à necessidade de controle externo ao processo produtivo, etc.

A importância dada à consideração aos aspectos culturais, sociais, políticos e econômicos próprios de cada realidade também é um elemento importante da TS. A consideração destes elementos é possível por meio da participação dos atores sociais no processo de planejamento e desenvolvimento de TS, sem, contudo, dispensar a atuação de pesquisadores e/ou cientistas neste processo - a TS considera importante haver uma associação entre os diferentes saberes (o popular e o científico, por exemplo).

Outra questão importante é que a TS propõe transformações (já que identifica o sistema capitalista como gerador das mazelas sociais), tanto sob a perspectiva do marco teórico-conceitual, como sobre a realidade empírica. As transformações podem ser parciais ou radicais, conforme pode ser observado nas sete modalidades de adequação sócio técnica propostas por Dagnino, Brandão e Novaes (2010), conforme seguem: o simples uso da TC, desde que haja uma modificação nos resultados do processo produtivo (descentralizando-o); a apropriação da TC por um coletivo de produção; a revitalização ou repotenciamento de maquinários e equipamentos, a fim de aumentar sua vida útil para o uso por empreendimentos produtivos autogestionários; o ajustamento dos processos de trabalho ao formato da propriedade coletiva dos meios de produção e à autogestão; a busca por tecnologias existentes (alternativas tecnológicas), caso nenhuma das modalidades anteriores tenham sido suficientes para resolver os problemas sociais (de empreendimentos produtivos autogestionários, por exemplos).

Uma vez tendo esgotado a busca por alternativas tecnológicas, é preciso haver a incorporação de conhecimento científico-tecnológico já existente para o desenvolvimento de tecnologias para a solução dos problemas sociais, ou "processos de inovação de tipo incremental, isolados ou em conjunto com centros de pesquisa e desenvolvimento (P\&D) ou universidades". Por fim, o esgotamento da modalidade anterior exige a incorporação de conhecimento científico-tecnológico novo ou os "processos de inovação de tipo radical que tendem a demandar o concurso de centros de P\&D ou universidades e que implicam a exploração da fronteira do conhecimento" (DAGNINO; BRANDÃO \& NOVAES, 2010, p. 102-103).

Por fim, vale salientar que a TS exige a construção de uma sociedade sustentável em diversos âmbitos - social, econômico, cultural e ambiental. Assim, a questão ambiental é abordada no sentido de se pensar uma sociedade que considere os aspectos referentes à preservação ambiental. Outra questão importante a ser destacada é com relação ao papel das políticas públicas. Uma vez que o Estado deve se preocupar em gerar as condições para solucionar os problemas sociais (especialmente, promover a inclusão social), apoiar e fomentar o desenvolvimento de TS parece ser um caminho viável e importante.

As discussões sobre desenvolvimento rural não se distanciam muito das reflexões sobre TS. Isso porque o desenvolvimento rural surgiu num momento de profunda crise econômica e agudização dos problemas sociais no país e, portanto, pautando a questão da concentração fundiária e da pobreza rural como temáticas que embasam a crítica ao modelo capitalista de produção, também considerado o gerador destas mazelas. Neste contexto, o entendimento de que o mundo rural não era homogêneo foi de fundamental importância, por garantir que o olhar dos pesquisadores se voltaria para a pequena agricultura familiar, e com isso, anunciasse a necessidade de uma atuação diferenciada do Estado no sentido de apoiar e fomentar estas práticas. Assim, uma vez sendo a pequena agricultura (familiar) diferente da grande agricultura produtora de commodities, é preciso uma atuação diferenciada do Estado com relação a este segmento. Assim, abriu-se caminho para as políticas públicas voltadas para a agricultura familiar, de maneira a fomentá-la.

O desenvolvimento rural não se limita apenas ao crescimento agrícola ou ao acesso à terra. Ele exige que haja condições básicas para se criar uma nova realidade no rural brasileiro, o que inclui propiciar aos atores do rural as condições necessárias para se alterar o ambiente institucional em favor de uma proposta de desenvolvimento rural que, por sua vez, exige a transferência de recursos, por parte do Estado, mas também, a mobilização das forças sociais locais, dando origem às novas instituições que têm condições para impulsionar o desenvolvimento regional (ABRAMOVAY, 1999; 2000). Assim, uma proposta que deve unir os diferentes atores de um território, numa perspectiva de atuação de várias instituições se alinha a ideia de construção coletiva da TS.

Uma questão interessante para reflexão é que o desenvolvimento rural é um processo que resulta de uma conjunção de forças. Logo, para que haja desenvolvimento rural, é preciso que haja uma importante colaboração de diferentes instituições capazes de alavancar um modelo de desenvolvimento capaz de gerar benefícios para o conjunto dos atores que coexistem em determinado espaço. Vale destacar que uma das mais importantes instituições 
é o Estado - instituição capaz de desenvolver políticas públicas voltadas a este fim, articular os diferentes atores, promover financiamento, etc.

$\mathrm{Na}$ busca de relacionar as temáticas deste trabalho, vale destacar, ainda, que, conforme Herrera (2010), o conhecimento empírico local nas áreas rurais dos países subdesenvolvidos tem sido de suma importância para viabilizar os processos produtivos, e isso se aplica especialmente aos pequenos produtores que não têm acesso às modernas tecnologias.

Las poblaciones locales (...) han tenido que desarrollar a través de una larga experiencia métodos y tecnologías de producción compatibles con el ambiente físico como una condición para la supervivencia. El análisis de esas tecnologías, y del conocimiento contenido en ellas, es el mejor atajo para conocer condiciones medioambientales que de otra manera tomaría un largo tiempo entender (HERRERA, 2010, p. 38).

O foco no local, presente nas reflexões sobre o desenvolvimento rural indica a necessidade de um olhar local para a dinâmica do desenvolvimento. Isto implica observar algumas particularidades da proposta, como o fato de que, para além dos fatores econômicos, o desenvolvimento deve ter em conta os aspectos sociais, políticos, culturais, de sustentabilidade ambiental. Além disso, o desenvolvimento rural tem como horizonte práticas que se alinhem à dinâmica do desenvolvimento territorial, conforme mencionado por Abramovay (2000).

Vale destacar que o desenvolvimento econômico, neste ínterim, teria como foco o social (contrapondo-se a um estilo de crescimento per se). Outro ponto importante é a participação dos atores neste processo como forma de considerar os diferentes aspectos relacionados à dinâmica territorial. Ou seja, as tecnologias sociais estão presentes nos ambientes rurais, sendo desenvolvidas para (e pelos) atores dos ambientes rurais, que se veem obrigados a buscar soluções para os problemas que enfrentam, especialmente relacionados ao acesso às tecnologias.

Assim, para além da valorização dos saberes locais (elemento importante nos conceitos de TS), fica evidente a questão da participação local (que, por sua vez, se alinha à proposta de desenvolvimento local). Apenas por meio destes elementos é que é possível desenvolver planos e projetos de desenvolvimento local que estejam de acordo com as características e necessidades das localidades. Para tal, Herrera (2010) considera que o desenvolvimento de tecnologias para os setores rurais menos favorecidos deve ser feito por meio de uma interação dos próprios atores locais e pesquisadores que também tenham algum tipo de relação com o local, a fim de garantir que estas tecnologias também estejam de acordo com as características e necessidades locais. Além disso, a contribuição das discussões sobre desenvolvimento sustentável também contribuiu para este novo enfoque, de maneira que é possível afirmar a importância desta temática nas discussões sobre desenvolvimento rural.

É notório que existe forte relação entre a produção e utilização de conhecimentos e tecnologias e os processos para o desenvolvimento ou manutenção de desigualdades persistentes no mundo rural - que envolvem disputas concretas por modelos de desenvolvimento ambiental e rural, territorial e entre culturas e práticas agrícolas. No Brasil vem prevalecendo a condição histórica de concentração fundiária e as concepções de desenvolvimento pouco preocupadas com aspectos locais, sociais e ambientais nos mais diversos âmbitos. Assim como a proposta de TS, que se contrapõem em contraposição ao modelo hegemônico capitalista, esta realidade fortalece as propostas para o desenvolvimento rural, como contraposição ao modelo hegemônico, que é concentrador (fundiário e de rendas) e gerador de pobreza rural.

$\mathrm{Na}$ mesma linha, a proposta da Agroecologia se alinha a ambas as propostas, por se contrapor a um modelo hegemônico predador e gerador de mazelas de diversos tipos - sociais, ambientais, culturais, etc.

A difusão dos conhecimentos e dos pacotes tecnológicos da chamada "Revolução Verde” (décadas de 1960 e 1970) trouxe consequências importantes para a transformação da matriz produtiva agrícola e sua "modernização". A dita "modernização da agricultura” é alicerçada também em "tecnologias convencionais agrícolas” que foram e são fundamentais para ampliação de uma agricultura industrial, altamente dependente de insumos químicos (incluindo agrotóxicos) e de modos de produção via grandes extensões de monocultivos, ou seja, concentradora de terra, que expulsa a "gente da terra" e reduz drasticamente a diversidade dos cultivos agrícolas e socioambiental. Esse modelo se choca diretamente com a produção agrícola em bases familiares ou ainda em bases familiares e agroecológicas (TAIT, 2017, p. 51-53).

As transformações que marcam o surgimento de um modelo hegemônico de agricultura industrial na América Latina lograram incrementar a produtividade de alguns cultivos de exportação. Mas, em contrapartida, tiveram impactos sociais negativos, territorial e ambiental, que acentuaram a degradação e concentração da terra e a perda de autonomia dos pequenos agricultores (PENGUE, 2005).

A forma como se configura atualmente a agricultura e também o sistema alimentar mundial tem consequências diretas relativas à quantidade e qualidade do acesso ao alimento. Sobre este tema, é emblemática a declaração de Maria Emília Pacheco, ex-presidente do Conselho Nacional de Segurança Alimentar e Nutricional (Consea), durante o Seminário Internacional "Alimento e Nutrição no Contexto dos Objetivos de Desenvolvimento do Milênio”, realizado em maio de 2014. Segundo ela, entre os fatores responsáveis pela alta no preço dos alimentos e as restrições de acesso pelos grupos sociais mais vulneráveis estão a tomada das áreas cultiváveis para o plantio de 
biocombustíveis, mudanças climáticas e, principalmente, a especulação realizada pelos mercados financeiros com os alimentos (TAIT, 2015, p. 47).

Ao aproximar a crítica à tecnologia convencional e a proposta da tecnologia social da crítica à agricultura industrial e proposta da agroecologia no Brasil discutimos algumas apostas teóricas que podem potencializar novas práticas dentro da agricultura familiar de base agroecológica. As tecnologias convencionais agrícolas são orientadas para grandes propriedades, mercado internacional e suas cotações, poucas variedades de cultivos, tendo na maximização da produção desta única variedade (ou de poucas variedades agrícolas) o seu objetivo central.

No Brasil, segundo informações do Censo Agropecuário de 2006, a soja foi à cultura que mais cresceu ( $88 \%$ nos últimos 10 anos), sendo destacada a expansão da fronteira agrícola para as regiões do Mato Grosso e Amazônia. A maior quantidade de uso de agrotóxicos ${ }^{3}$ se dá justamente nessas regiões de expansão de cultivo de soja no centro-oeste brasileiro, nos estados de Mato Grosso, Mato Grosso do Sul e Goiás, além do estado de São Paulo na região Sudeste e Paraná e Rio Grande do Sul na região Sul, estados que também entre os maiores produtores e consumidores. Nos cultivos de soja, milho e cana, que juntos corresponderam a 76\% da área plantada no Brasil em 2015, pulverizou-se 899 milhões de litros de agrotóxicos (PIGNATI, 2017, p. 3288).

No caso das tecnologias sociais estão principalmente enfocadas na adaptação aos produtores familiares e menores propriedades, no atendimento das necessidades familiares, locais e regionais (principalmente na produção de alimentos) e valorizam os conhecimentos, culturas e potenciais dos agricultores e agricultoras.

Assim, para efetivação dos processos de transição agroecológica e de desenvolvimento de tecnologias sociais é necessária uma aproximação crescente entre agroecologia e alternativas tecnológicas dentro dos parâmetros da tecnologia social. Na verdade, poderíamos arriscar uma afirmação de que uma tecnologia para ser agroecológica precisa ser também social e uma tecnologia social agrícola, muito provavelmente, seria desenvolvida e inserida em práticas agroecológicas.

\section{Referências}

ALTIERI, M. A. Agroecologia: bases científicas para uma agricultura sustentável. Guaíba: Agropecuária, 2002.

ALTIERI, M. A.; NICHOLLS, C. I. Agroecología: teoría y práctica para una agricultura sustentable. México: PNUMA, 2000.

Altieri, M. NiChOlls, C.; MONTAlBA, R. Technological Approaches to Sustainable Agriculture at a Crossroads: An Agroecological Perspective. Sustainability 2017, 9(3), 349.

ARTICULAÇÃO NACIONAL DE AGROECOLOGIA (ANA). Disponível em: https://agroecologia.org.br/. Acesso em 05/11/2019.

BERGAMASCO, S. M. P. P. Agricultura Familiar, Agroecologia e Políticas Públicas. In: Marco Referencial de Agroecologia - Rede de Agroecologia da UNICAMP (coord. FAGUNDES e SOUZA), Biblioteca da UNICAMP, 2017.

BOMBARDI, L. M. Geografia do Uso de Agrotóxicos no Brasil e Conexões com a União Europeia. São Paulo FFLCH/USP, 2017.

CAPORAL F; COSTABEBER, J. A. Agroecologia: alguns conceitos e princípios. Brasília: MDA/SAF/DATERIICA. 2004.

CAPORAl F; COSTABEBER, J. A. Agroecologia e Desenvolvimento Sustentável: perspectiva para uma nova extensão rural. Porto Alegre. V 1, N 1 jan/mar 2000.

CONSEA. A construção do sistema e da política nacional de segurança alimentar e nutricional: a experiência brasileira. Cosea e FAO, Brasília, 2009.

3 O livro "Geografia do uso de Agrotóxicos no Brasil e conexões com União Europeia" (BOMBARDI, 2017) reuniu um conjunto de dados e mapas de fontes oficiais (com dados referentes ao período de 2007 a 2014) sobre a expansão da fronteira agrícola do agronegócio e suas principais commodities (soja, milho, cana-de-açúcar, trigo e eucalipto) e ampliação do uso de agrotóxicos (sendo o mais vendido no país o glifosato), a intoxicação e morte por intoxicação (notificadas e municípios que produzem estes dados) que atingem em maior número de homens, mas também mulheres, crianças e bebês - uma média de 148 mortes por ano e 300 bebês com intoxicação entre 2007 e 2014 - e o aumento de tentativas de suicídios utilizando agrotóxicos. 
COStABeBER, J. A. Transição Agroecológica - rumo a sustentabilidade. Revista Agriculturas: Experiências em Agroecologia, caminhos para transição. Rio de Janeiro: AS-PTA, v 3 n 3, out. 2006.

DAGNiNO, R. A tecnologia social e seus desafios. In: Tecnologia social: uma estratégia para o desenvolvimento. Fundação Banco do Brasil: Rio de Janeiro, 2004.

DAGNINO, R. Tecnologia Social: contribuições conceituais e metodológicas. EDUEPB e Editora Insular, 2014.

DAGNINO, R; BRANDÃO, F.C.; NOVAES, H.T. Sobre o marco analítico conceitual da tecnologia social. In: Tecnologia social: uma estratégia para o desenvolvimento. Fundação Banco do Brasil: Rio de Janeiro, 2004.

FRANÇA, C. G. DE GROSSI; MARQUES, M.; AZEVEDO, V. O censo agropecuário 2006 e a agricultura familiar no Brasil, MDA, 2009.

FUNDAÇÃO BANCO DO BRASIL (FBB). Tecnologia Social. Disponível em: https://www.fbb.org.br/pt-br/ra/ conteudo/tecnologia-social. Acesso em 27/11/2019.

GLIESSMAN, S. R. (ed.). Agroecology: researching the ecological basis for sustainable agriculture. New York: Springer-Verlag, 1990.

GLIESSMAN, S. R. Agroecologia: processos ecológicos em agricultura sustentável. Porto Alegre: Editora da Universidade - UFRGS, 2000.

GLIESSMAN, S., 2002, Agroecología: procesos ecológicos en agricultura sostenible, Catie, Turrialba.

GUZMÁN CASADO, G.; GONZÁLEZ DE MOLINA, M.; SEVILLA GUZMÁN, E. (Coord.). Introducción a la Agroecología como desarrollo rural sostenible. Madrid: Ediciones Mundi-Prensa, 2000.

HERRERA, Amilcar. La generación de tecnologías en las zonas rurales. In: DAGNINO, Renato (org.). Tecnologia social: ferramenta para construir outra sociedade (2. ed. rev. e ampl). Campinas/SP: Komedi, 2010.

INFORME DA OXFAM BRASIL. Terra, agricultura e desigualdades no Brasil rural. Novembro de 2016. Disponível em: https://oxfam.org.br/justica-social-e-economica/terras-e-desigualdade/. Acesso em 04/11/2019.

MOURA, I. F. Agroecologia na agenda governamental brasileira: trajetórias no período 2003-2014. 2016. Tese (Doutorado). Universidade Federal Rural do Rio de Janeiro, 2016.

PENA, Jacques de Oliveira. Tecnologia Social e o Desenvolvimento Rural. In: OTTERLOO, Aldalice. et al. (orgs.). Tecnologias Sociais: Caminhos para a sustentabilidade. Brasília/DF: s.n, 2009.

PENGUE, W., 2005, Agricultura industrial y transnacionalizacion en América Latina: ¿La transgenesis de un Continente?, PNUMA, México.

PIGNATI, W. A. et al., 2017, "Distribuição espacial do uso de agrotóxicos no Brasil: uma ferramenta para a Vigilância em Saúde”, Ciênc. saúde coletiva, vol. 22, n. ำ10 (Oct), Rio de Janeiro, p. 3281-3293.

RUTKOWSKI, Jaqueline. Rede de Tecnologias Sociais: pode a tecnologia proporcionar desenvolvimento social? In: LIANZA, S.; ADDOR, F (org). Tecnologia e desenvolvimento social e solidário. Porto Alegre/RS: Editora UFRGS, 2005.

SCHNEIDER, Sergio. Situando o desenvolvimento rural no Brasil: o contexto e as questões em debate. Rev.

Econ. Polit., São Paulo, v. 30, n. 3, p. 511-531, Sept. 2010.

TAIT, M. M. L.Tecnologia Social. In: Marco Referencial de Agroecologia - Rede de Agroecologia da UNICAMP (coord. FAGUNDES e SOUZA), Biblioteca da UNICAMP, 2017.

TAIT, M. M. L. Elas dizem não! Mulheres camponesas e resistência aos cultivos transgênicos. Campinas: Librum Editora, 2015. 
TAIT, M. M. L, BIASE, L.; FAGUNDES, G. G. Agroecologia e Ecologização de Ecossistemas. In: Marco Referencial de Agroecologia - Rede de Agroecologia da UNICAMP (coord. FAGUNDES e SOUZA), Biblioteca da UNICAMP, 2017.

TAIT, M. M. L. e BRITO, V. J. Questões sobre gênero e tecnologia na construção da agroecologia. SCIENTIAE STUDIA, v.15, p.73, 2017.

TOLEDO, V. M., “A agroecologia é uma revolução epistemológica”. Revista Agriculturas, vol. 13, n. ${ }^{\circ}$ 1, p. 42-5, 2016.

URCHEI, M. A. Agroecologia e a crise da sociedade atual. In: Marco Referencial de Agroecologia - Rede de Agroecologia da UNICAMP (coord. FAGUNDES e SOUZA), Biblioteca da UNICAMP, 2017.

WEZEL, A. et al., 2009, “Agroecology as a science, a movement and a practice: a review”, Agronomy for Sustainable Development, vol. 29, n. ${ }^{\circ}$, p. 503-15. 